\title{
PERINATAL OUTCOME OF HYPERTENSIVE PREgNANT WOMEN IS RELATED TO THE SEVERITY OF PREECLAMPSIA
}

\author{
Marciano Anselmini' ${ }^{1}$ Lucas Kreutz Rodrigues², Bruna Balestrin ${ }^{2}$, \\ Daniel de Paula Santana², Gisely Freitas ${ }^{2}$, \\ Leonardo Kreutz Rodrigues ${ }^{2}$, \\ Francisco Maximiliano Pancich Gallarreta ${ }^{3}$, Cristine Kolling Konopka ${ }^{3}$
}

Clin Biomed Res. 2018;38(2):116-122

1 Residência Médica em Ginecologia e Obstetrícia, Hospital Universitário de Santa Maria (HUSM), Universidade Federal de Santa Maria (UFSM). Santa Maria (RS), Brasil.

2 Curso de Medicina da Universidade Federal de Santa Maria (UFSM). Santa Maria (RS), Brasil.

3 Departamento de Ginecologia e Obstetrícia, Centro de Ciências da Saúde, Universidade Federal de Santa Maria (UFSM). Santa Maria (RS), Brasil.

Corresponding author: Cristine Kolling Konopka cristine.ufsm@gmail.com Departamento de Ginecologia e Obstetrícia, Centro de Ciências da Saúde (CCS), Universidade Federal de Santa Maria (UFSM)

Av. Roraima, 1000.

97105-900, Cidade Universitária,

Camobi, Santa Maria, RS, Brasil.

\section{ABSTRACT}

Introduction: Hypertension in pregnancy plays a key role in perinatal morbidity and mortality. This study aims to analyze maternal and perinatal outcomes associated with hypertension in pregnant women.

Methods: A prospective longitudinal study was conducted at the University Hospital of Santa Maria, RS, Brazil, involving hypertensive pregnant women admitted for delivery. The results were analyzed using the chi-square test and the Mann-Whitney test.

Results: Of the 162 hypertensive pregnant women studied, $61.1 \%$ were diagnosed with preeclampsia. Cesarean section was the most frequent mode of delivery $(79.6 \%)$. Overall, $46.2 \%$ of newborns were premature; of these, $23.4 \%$ required intensive neonatal care. Preeclampsia and severe preeclampsia were associated with prematurity in $56.2 \%$ of cases $(p=0.011)$ and $75.7 \%$ of cases $(p=0.004)$, respectively. Severe preeclampsia was associated with neonatal complications (45.9\%), and no neonatal complications were associated with mild preeclampsia in $78 \%(p=0.014)$ and gestational hypertension in $96 \%(p=0.001)$. Neonatal deaths occurred in $11.1 \%$ of cases admitted to the neonatal intensive care unit, corresponding to a neonatal mortality rate of 24 per 1,000 live births.

Conclusions: The association of severe preeclampsia with prematurity and adverse perinatal outcomes corroborates the need for care of these laboring women in referral centers with specialized neonatal care.

Keywords: Hypertension; pregnancy; pre-eclampsia; perinatal outcome; neonatal complications

Hypertensive disorders of pregnancy occur in $5-10 \%$ of pregnancies and represents one of the main causes of maternal and perinatal morbidity and mortality. The most important of these disorders is preeclampsia (PE), which affects approximately $3 \%$ of pregnant women ${ }^{1}$. In our setting, a study conducted by Vettorazzi et al. in Porto Alegre, state of Rio Grande do Sul, found that $6.7 \%$ of primiparous mothers had mild $P E$ and $2.9 \%$ had severe $\mathrm{PE}^{2}$.

The present study classifies hypertension in pregnancy into four categories ${ }^{3,4}$ : $\mathrm{PE}$ alone; chronic hypertension; chronic hypertension with superimposed PE; and gestational (transient) hypertension. Chronic hypertension is defined as high blood pressure (BP) known to predate gestation or detected before 20 weeks of gestation. Conversely, later-onset hypertension is classified according to proteinuria: gestational hypertension is diagnosed in the absence of proteinuria, i.e., when 24-hour excretion does not exceed $300 \mathrm{mg}$ in 24 hours or protein/creatinine ratio does not exceed $3.0 \mathrm{mg} / \mathrm{dL}$; whereas $\mathrm{PE}$ is diagnosed in the presence of proteinuria, i.e., when 24-hour excretion exceeds $300 \mathrm{mg}$ in 24 hours or protein/creatinine ratio exceeds $3.0 \mathrm{mg} / \mathrm{dL}$. PE may overlap with chronic hypertension, characterizing a condition known as chronic hypertension with superimposed PE. In the absence of proteinuria, 
$\mathrm{PE}$ is defined as hypertension occurring in association with platelet count less than $100,000 \mathrm{~mm}^{3}$, serum creatinine $\geq 1.1 \mathrm{mg} / \mathrm{dL}$ or doubling of serum creatinine in the absence of other renal disease, elevation of liver enzymes to twice the normal concentration, pulmonary edema, cerebral edema, and/or visual disturbances ${ }^{4}$.

PE, HELLP syndrome (acronym for hemolysis, elevated levels of liver enzymes, and low platelet count), and eclampsia (PE accompanied with seizures) represent increasing severities of the spectrum of hypertensive disorders of pregnancy ${ }^{1}$. PE may also lead to fetal growth restriction, prematurity, abruptio placentae, and, in more severe cases, maternal and fetal death ${ }^{3,5}$. HELLP syndrome, a serious complication of PE characterized by hemolysis, elevated liver enzymes, and low platelet count, occurs in $0.5-0.9 \%$ of all pregnancies and in $10-20 \%$ of cases with severe $\mathrm{PE}^{6,7}$. Additionally, it is a progressive disease leading to severe complications and is strongly associated with maternal mortality ${ }^{8}$.

Among hypertensive disorders of pregnancy, $\mathrm{PE}$ is the one posing the greatest risk for mortality, especially in its severe form or when occurring before 34 weeks' gestation ${ }^{9}$. Maternal recovery from PE is initiated only after delivery ${ }^{10}$. In cases of chronic or gestational hypertension, there were no significant differences in the risk of pregnancy loss, high-level neonatal care, or overall maternal complications among women assigned to tight control of hypertension (target diastolic BP, $85 \mathrm{mmHg}$ ) vs. those assigned to a less-tight control (target diastolic BP, $100 \mathrm{mmHg}$ ). However, less-tight control was associated with a significantly higher frequency of severe maternal hypertension ${ }^{11}$. In pregnant women with chronic hypertension, antihypertensive treatment was found to reduce the risk of severe hypertension ${ }^{12}$.

Hypertension is one of the leading causes of maternal death in several countries. A recent systematic analysis ${ }^{13}$ revealed that it is the second leading cause of maternal death worldwide $(14.0 \%)$, after hemorrhage $(27.0 \%)$ and before sepsis $(10.7 \%)$. Overall, 10 to $15 \%$ of direct maternal deaths are associated with PE and eclampsia in developing countries ${ }^{14}$. In Brazil, hypertension in pregnancy is the leading cause of maternal mortality, accounting for nearly $25 \%$ of maternal deaths in Brazilian state capitals, followed by hemorrhage ${ }^{15,16}$.

Given the importance of the topic and its considerable impact on maternal and perinatal morbidity and mortality, the present study aimed to assess maternal, laboratory (including serum levels of uric acid), fetal, and neonatal factors associated with hypertension in pregnancy, as well as maternal and perinatal outcomes in hypertensive pregnant women admitted for delivery to Hospital Universitário de Santa Maria (HUSM), Santa Maria, southern Brazil.

\section{METHODS}

A prospective, longitudinal study was conducted to assess 162 pregnant women who met criteria for hypertension, selected from 1,982 mothers who gave birth at the HUSM obstetric unit from June 2011 to June 2012. The research was carried out in accordance with the ethical principles of the Declaration of Helsinki of 2008. All participants signed a written consent form that ensured data confidentiality and voluntary participation. This study was approved by the Research Ethics Committee of Universidade Federal de Santa Maria (UFSM) under Certificate of Presentation Ethical Evaluation (CAAE) number 0066.0.243.000-11. Data from pregnant women and newborns (NBs) were collected using a standardized form during daily visits to the maternity ward and from medical records.

Hypertension in pregnancy was diagnosed according to the diagnostic criteria established by the American College of Obstetricians and Gynecologists ${ }^{4}$. For analysis purposes, data for PE alone and superimposed on chronic hypertension were grouped into one category. PE was considered mild in the absence of systemic involvement, and severe in the presence of such involvement, characterized by $B P \geq 160 / 110 \mathrm{mmHg}$, HELLP syndrome (thrombocytopenia, i.e., platelet count $<100.000 \mathrm{~mm}^{3}$; altered liver enzymes, i.e., lactate dehydrogenase $\geq 600$ international units [IU]/L, glutamic-oxaloacetic transaminase/ glutamic-pyruvic transaminase $\geq 70 \mathrm{UI} / \mathrm{L}$; and/or hemolysis), renal impairment (oliguria, i.e., urinary volume $<500 \mathrm{~mL}$ in 24 hours or altered renal function, i.e., creatinine $>1.1 \mathrm{mg} / \mathrm{dL}$ ), pulmonay edema (dispnea) and/or cerebral edema (altered mental status, headache, blurred vision, blindness, seizures). Laboratory criteria for the diagnosis of HELLP syndrome were those established by Sibai ${ }^{17}$. Uric acid was individually assessed for the association with disease severity (reference normal range $<4.5 \mathrm{mg} / \mathrm{dL}$ ).

Gestational complications assessed in this study were HELLP syndrome, abruptio placentae, and maternal neurological and visual alterations.

Neonatal variables included prematurity, defined as birth at less than 37 weeks of gestational age (GA) as determined by the Capurro method; birth weight, with low birth weight defined as < 2,500 g; 1- and 5-minute Apgar scores, with depressed NB being those with 5-minute Apgar score $<7$ and vigorous NBs those with 5-minute Apgar score $\geq 7$; neonatal morbidity (admission to the neonatal intensive care unit; length of stay at the NICU); intercurrent diseases; 
and neonatal mortality rate. To enable the analysis of PE severity, preterm infants were divided into two categories: those born from 34 to 37 weeks' gestation and those born before 34 weeks' gestation. Intercurrent diseases were defined as any neonatal comorbidities occurring during NB's hospitalization.

Data obtained in this study were processed and analyzed using Statistical Package for Social Science (SPSS), version 15.0. Categorical variables were assessed with the chi-square test when assumptions of normality were met. Continuous variables were assessed with the Mann-Whitney test. The level of significance was set at $5 \%$.

\section{RESULTS}

Results for this study showed that, of the 162 hypertensive pregnant women admitted for delivery to the institution, $61.1 \%$ were diagnosed with $\mathrm{PE}, 50 \%$ of these with $\mathrm{PE}$ alone and $11 \%$ with PE superimposed on chronic hypertension (Table 1). In less severe syndromes, there was predominance of gestational hypertension (31.5\% of cases), followed by chronic hypertension (7.4\% of cases). The prevalence of hypertension in pregnancy during the study period was $8.17 \%$ (991 births/year and 81 cases of hypertension/year).

Mean age of participants was $27.3 \pm 7.1$ years, and the most common age range of patients with hypertension in pregnancy was 19-29 years old. The mean number of pregnancies was $2.5 \pm 1.7$, and mean number of previous deliveries was $2.2 \pm 1.4$. Primiparous mothers accounted for $37.7 \%$ of study participants, and primiparity was associated with the diagnosis of PE $(p=0.020)$. Of the 162 pregnant women, three had a twin pregnancy. Thus, the number of conceptuses was 165, totaling 158 live births. There were seven fetal deaths, of which five occurred in pregnant women with PE $(71 \%)$, and four neonatal deaths, all of which occurred in NBs of mothers with PE.

Cesarean section was the most frequent mode of delivery among hypertensive pregnant women, accounting for $79.6 \%$ of deliveries $(n=129)$. The most

Table 1: Distribution of cases according to the type of hypertension in pregnancy.

\begin{tabular}{lcr}
\hline \multicolumn{1}{c}{ Diagnosis } & $\begin{array}{c}\text { Number } \\
\text { of cases }\end{array}$ & $\%$ \\
\hline Preeclampsia & 81 & 50.0 \\
Chronic hypertension & 12 & 7.4 \\
Chronic hypertension + PE & 18 & 11.1 \\
Gestational hypertension & 51 & 31.5 \\
\hline
\end{tabular}

PE: preeclampsia. common indications for cesarean section were poorly-controlled, decompensated hypertension, repeated cesarean sections, failure of response to labor induction, and compromised fetal well-being. There was no significant association between type of hypertension and mode of delivery. However, when it comes to PE severity, the percentage of parturient women who underwent a cesarean section was $70.5 \%$ among those with mild PE and $92.3 \%$ among those with severe PE. Conversely, 1- and 5-minute Apgar scores were not associated with any type of hypertension.

A total of $46.2 \%$ of hypertensive pregnant women gave birth to preterm infants, $12.0 \%$ of which were born before 34 weeks' gestation. With regard to types of hypertension, chronic and gestational hypertension were found to be associated with gestational age $\geq 37$ weeks ( $p=0.011$ ), accounting for 66.7 and $70 \%$ of cases, respectively (Table 2 ). Conversely, PE (alone or superimposed on chronic hypertension) was associated with prematurity in $56.2 \%$ of cases, $15.6 \%$ of which occurred before 34 weeks' gestation. As for PE severity (Table 3), an association was observed between mild PE and term pregnancy, whereas severe PE was associated with premature births $(75.7 \%$ of cases), $24.3 \%$ of which occurred before 34 weeks' gestation $(p=0.004)$. There was also a significant association between type of hypertension and birth weight (Table 2), with birth weight $<2,500 \mathrm{~g}$ being associated with $P E$ and birth weight $\geq 2,500 \mathrm{~g}$ being associated with gestational hypertension ( $p=0.027)$. In terms of PE severity (Table 3 ), severe PE was associated with birth weight $<2,500 \mathrm{~g}$ in $59 \%$ of cases, and mild PE was associated with birth weight $\geq 2,500 \mathrm{~g}$ in $85.5 \%$ of cases ( $p=0.0001)$.

The most frequent neonatal complications were respiratory distress syndrome of the newborn, pneumonia, sepsis, and hyaline membrane disease, and most cases presented overlapping intercurrent diseases. An association was found between neonatal complications and type of hypertension (Table 2) and PE severity (Table 3). A total of $32.3 \%$ of NBs born to patients with $\mathrm{PE}$ developed complications; conversely, 83.3 and $96 \%$ of NBs born to mothers with chronic or gestational hypertension, respectively, did not develop complications $(p=0.001)$. Table 3 shows that absence of complications was also predominant in mild PE $(78 \%)$, whereas $45.9 \%$ of cases of severe PE were associated with complications $(p=0.014)$.

A total of $22.2 \%$ of neonates born to hypertensive pregnant mothers required hospitalization to the NICU; mean length of stay was 17 days, maximum of 67 days. An association was observed between PE (either alone or superimposed on chronic hypertension) and 
Table 2: Association between perinatal variables and type of hypertension in pregnancy.

\begin{tabular}{|c|c|c|c|c|}
\hline \multirow[b]{2}{*}{ Variables } & \multicolumn{4}{|c|}{ Type of hypertension } \\
\hline & $\begin{array}{l}\text { Preeclampsia } \\
\text { (alone and } \\
\text { superimposed } \\
\text { on chronic } \\
\text { hypertension) }\end{array}$ & $\begin{array}{c}\text { Chronic } \\
\text { hypertension }\end{array}$ & $\begin{array}{c}\text { Gestational } \\
\text { hypertension }\end{array}$ & $\mathbf{P}$ \\
\hline \multicolumn{5}{|l|}{ Gestational age } \\
\hline$<37$ weeks & $54(56.2 \%)$ & $4(33.3 \%)$ & $15(30.0 \%)$ & \\
\hline$\geq 37$ weeks & $42(43.8 \%)$ & $8(66.7 \%)$ & $35(70.0 \%)$ & $0.011^{*}$ \\
\hline \multicolumn{5}{|l|}{ Birth weight (grams) } \\
\hline$<2,500$ & $33(32.7 \%)$ & $2(16.7 \%)$ & $7(13.5 \%)$ & $0.027^{*}$ \\
\hline$\geq 2,500$ & $68(67.3 \%)$ & $10(83.3 \%)$ & $45(86.5 \%)$ & \\
\hline \multicolumn{5}{|l|}{ Neonatal complications } \\
\hline Yes & $31(32.3 \%)$ & $2(16.7 \%)$ & $2(4.0 \%)$ & $0.001^{*}$ \\
\hline No & $65(67.7 \%)$ & $10(83.3 \%)$ & $48(96.0 \%)$ & \\
\hline \multicolumn{5}{|l|}{ Admission to the NICU } \\
\hline Yes & $32(33.3 \%)$ & $2(16.7 \%)$ & $3(6.0 \%)$ & $0.001^{*}$ \\
\hline No & $64(66.7 \%)$ & $10(83.3 \%)$ & $47(94.0 \%)$ & \\
\hline \multicolumn{5}{|l|}{ NB outcome at discharge } \\
\hline Alive & $92(91.1)$ & $12(100 \%)$ & $50(96.1 \%)$ & - \\
\hline Death & $9(8.9 \%)$ & $0(0.0 \%)$ & $2(3.9 \%)$ & \\
\hline \multicolumn{5}{|l|}{ Maternal complications } \\
\hline Yes & $17(17.2 \%)$ & $2(16.7 \%)$ & $0(0.0 \%)$ & - \\
\hline No & $82(82.8 \%)$ & $10(83.3 \%)$ & $51(100.0 \%)$ & \\
\hline
\end{tabular}

Table 3: Classification of preeclampsia and association with neonatal conditions.

\begin{tabular}{|c|c|c|c|}
\hline \multirow{2}{*}{ Variables } & \multicolumn{3}{|c|}{ Classification of preeclampsia } \\
\hline & Mild PE & Severe PE & $\mathbf{P}$ \\
\hline \multicolumn{4}{|l|}{ GA at birth } \\
\hline$<34$ weeks & $5(8.5 \%)$ & $9(24.3 \%)$ & $0.004^{*}$ \\
\hline 34-37 weeks & $20(33.9 \%)$ & $19(51.4 \%)$ & \\
\hline$\geq 37$ weeks & $34(57.6 \%)$ & $9(24.3 \%)$ & \\
\hline Birth weight & & & $0.0001^{*}$ \\
\hline$<2,500 \mathrm{~g}$ & $9(14.5 \%)$ & $23(59.0 \%)$ & \\
\hline$\geq 2,500 \mathrm{~g}$ & $53(85.5 \%)$ & $16(41.0 \%)$ & \\
\hline Neonatal complications & & & $0.014^{*}$ \\
\hline Yes & $13(22.0 \%)$ & $17(45.9 \%)$ & \\
\hline No & $46(78.0 \%)$ & $20(54.1 \%)$ & \\
\hline Admission to the NICU & & & $0.007^{*}$ \\
\hline Yes & $13(22.0 \%)$ & $18(48.6 \%)$ & \\
\hline No & $46(78.0 \%)$ & $19(51.4 \%)$ & \\
\hline NB outcome at discharge & & & $0.587^{*}$ \\
\hline Alive & $56(90.3 \%)$ & $36(92.3 \%)$ & \\
\hline Death & $6(9.7 \%)$ & $3(7.7 \%)$ & \\
\hline Maternal complications & & & $0.0001^{*}$ \\
\hline Yes & $1(1.6 \%)$ & $16(41.0 \%)$ & \\
\hline No & $60(98.4 \%)$ & $23(59.0 \%)$ & \\
\hline
\end{tabular}

PE: preeclampsia (including PE alone and superimposed on chronic hypertension); GA: gestational age; NICU: neonatal intensive care unit. $p$-value for chi-square test and considered significant $\left({ }^{*}\right)$ at $<0.05$. 
requirement of admission to the $\mathrm{NICU}$ in $33.3 \%$ of cases (Table 2), as well as between chronic and gestational hypertension and no requirement for admission to the NICU in 83.3 and $94 \%$, respectively ( $p=0.001$ ). There was an association between PE severity and admission to the NICU (Table 3). Admission to the NICU were significantly associated with severe PE in $48.6 \%$ of cases, and no requirement of admission was associated with mild PE in $78 \%$ of the cases $(p=0.007)$.

Most cases (87.6\%) evolved without maternal complications. The most frequent complications were HELLP syndrome (13 cases), abruptio placentae (4 cases), and eclampsia (1 case). With regard to maternal complications and serum uric acid, it was found that pregnant women who did not develop complications had lower uric acid levels $(4.63 \pm 1.45 \mathrm{mg} / \mathrm{dL})$ compared with those who developed complications $(6.41 \pm 2.06 \mathrm{mg} / \mathrm{dL})$, with $p=0.0001$. There were no cases of maternal death in the study population.

\section{DISCUSSION}

Hypertensive disorders are the most frequent complication in pregnancy. However, the impact of hypertension on maternal, fetal, and neonatal outcomes was associated with disease severity ${ }^{18,19}$. Nearly $60 \%$ of study participants were diagnosed with $\mathrm{PE}$, either alone or superimposed on chronic hypertension. The findings obtained in this study show that mild PE, as well as well-controlled chronic and gestational hypertension, is not associated with neonatal complications and requirement of admission to the NICU.

Although the prognosis of mild PE is favorable, its more severe forms are a major cause of perinatal and maternal morbidity and mortality ${ }^{19,20}$. In this study, most preterm infants, low birth weight infants, NBs with neonatal complications, and those requiring admission to the NICU were born to mothers with severe $\mathrm{PE}$, and most cases of fetal and neonatal death occurred in patients with PE. Neonatal mortality was high among cases with PE, especially in its severe forms, being even higher after eclampsia ${ }^{19}$. Our study found only one case of eclampsia, which was not associated with neonatal complications.

Pregnant women at risk for PE may be identified by the presence of epidemiological and clinical factors such as age, parity, presence of chronic hypertension, antiphospholipid antibody syndrome, previous PE, gestational diabetes, assisted reproduction, body mass index $>30 \mathrm{~kg} / \mathrm{m}^{21-23}$. With regard to maternal age, the mean age of pregnant women (27.3 years) was similar to that observed in other studies ${ }^{21,24,25}$.
When it comes to the association between parity and hypertension in pregnancy, the present study found that $37.7 \%$ of participants were primiparous mothers, a percentage lower than that reported in the literature, where nulliparous women accounted for $44 \%{ }^{21}$ and $55 \%{ }^{25}$ of hypertensive patients. However, an association was observed between hypertensive primiparous mothers and diagnosis of PE. These findings are consistent with the results of a systematic review conducted by Duckitt \& Harrington in 2005, which showed that nulliparous women have a nearly three-fold increased risk for $\mathrm{PE}^{24}$. Young age of hypertensive pregnant women and association of PE with first pregnancy highlight the need for universal prenatal care and risk detection, with follow-up of at-risk pregnant women at referral services.

Previous studies show a clear increase in the number of cesarean sections in hypertensive pregnant women, being the mode of delivery of 75,9 to $78,4 \%$ births among women with $\mathrm{PE}^{21,26}$. Literature findings are consistent with those of this study, which reported an overall percentage of $79.6 \%$ of cesarean sections among hypertensive pregnant women, reaching $70.5 \%$ in cases of mild PE and $92.3 \%$ in cases of severe PE. Our data reinforce previously described results showing that hypertensive syndromes led to an up to 3.4-fold increase in the number of cesarean sections ${ }^{27}$. In our sample, this was more remarkable in cases of severe $\mathrm{PE}$, when maternal or fetal conditions, often unfavorable, may not allow for induction of vaginal delivery.

As for neonatal findings, nearly $25 \%$ of hypertensive pregnant women assessed in this study gave birth to low birth weight infants, which demonstrates the negative consequences of hypertensive syndrome in pregnancy. The percentage of low birth weight was significantly different between the groups, being significantly higher in patients with $\mathrm{PE}$ $(30.9 \%)$, and severe PE was associated with birth weight $<2,500 \mathrm{~g}(59 \%)$. These findings were similar to those of Langenveld et al., who described that PE was associated with small for GA infants ${ }^{28}$, and of Yücesoy et al., who found an association between low birth weight and severe $\mathrm{PE}^{29}$.

Abnormal placentation is the cause of $\mathrm{PE}^{30}$ and insufficient placental functioning leads to intrauterine growth restriction, whose presence worsens neonatal prognosis, increasing the likelihood of preterm labor and death related to birth weight ${ }^{31,32}$. In the present study, hypertensive pregnant women diagnosed with PE accounted for most preterm deliveries, with prematurity rates reaching $75.7 \%$ among severe PE cases. The high frequency of preterm infants among these cases may be explained by the fact that pregnancy interruption is the only effective 
treatment for $P E$, resulting in a shorter duration of pregnancy ${ }^{33}$. These findings point to the high rate of perinatal complications resulting from prematurity and the strong association between $\mathrm{PE}$ and prematurity. This may explain the high rates of admissions to the NICU in our sample, since one third of NBs of pregnant women with PE and a half of NBs of pregnant women with severe $P E$ required intensive care.

Also worthy of note is the high neonatal mortality observed in the present study. Brazil has a mortality rate of 10.6 neonatal deaths by 1,000 live births ${ }^{34}$. A comparative analysis found a mortality rate of 24 neonatal deaths per 1,000 live births, showing a high neonatal mortality rate due to hypertension in pregnancy.

In our study population, there were few cases of maternal complications and no cases of maternal death. HELLP syndrome occurred in $8 \%$ of cases, which is consistent with the literature reporting an incidence of 2 to $12 \%{ }^{35}$.

The study duration of 1 year may be considered a weakness of this research, because less frequent maternal complications, such as disseminated intravascular coagulation (DIC), multiple organ failure, and death, were not observed. Conversely, the strength of this study is its prospective prospective design that included all hypertensive pregnant women who gave birth at HUSM during the study period. Furthermore, infants were followed up during the entire neonatal period, which allowed for the analysis of outcome of each case.

The main conclusion of the present study is that $P E$, especially in its severe form, increase the risk for adverse perinatal and neonatal outcomes, leading to a significant number of neonates admitted to the NICU and to high neonatal mortality. Hence, management of hypertensive in pregnancy should include practices that promote actions focused on prevention and early diagnosis of preeclampsia and appropriate intervention in severe cases, thus minimizing maternal complications and harm to conceptuses and neonates.

\section{Conflicts of Interest}

The authors declare no conflicts of interest.

\section{REFERENCES}

1. Vest AR, Cho LS. Hypertension in pregnancy. Curr Atheroscler Rep. 2014;16(3):395. http://dx.doi. org/10.1007/s11883-013-0395-8. PMid:24477794.

2. Vettorazzi J, Vetori D, MartinsCosta S, Ramos JGL. Variação sazonal na prevalência de distúrbios hipertensivos da gestação entre primigestas do Sul do Brasil. Clin Biomed Res. 2016;36(1):11-7. http:// dx.doi.org/10.4322/2357-9730.58634.

3. Report of the national high blood pressure education program working group on high blood pressure in pregnancy. Am J Obstet Gynecol. 2000;183(1):S1-22. http://dx.doi. org/10.1067/mob.2000.107928. PMid:10920346.

4. American College of Obstetricians and Gynecologists. Women's Health Care Physicians. Hypertension in pregnancy. Washington: American College of Obstetricians and Gynecologists; 2013. [cited 2017 Sep 16]. Available from: http://www.acog. org/Resources_And_Publications/ Task_Force_and_Work_Group_ Reports/Hypertension_in_Pregnancy.
5. Orcy RB, Pedrini R, Piccinini P, Schroeder S, Costa SHM, Lopes Ramos JG, et al. Diagnóstico, fatores de risco e patogênese da pré-eclâmpsia. Clin Biomed Res. 2007;27(3):43-6.

6. Arulkumaran $\mathrm{N}$, Lightstone L. Severe pre-eclampsia and hypertensive crises. Best Pract Res Clin Obstet Gynaecol. 2013;27(6):877-84. http://dx.doi. org/10.1016/j.bpobgyn.2013.07.003. PMid:23962474.

7. Haram K, Svendsen E, Abildgaard U. The HELLP syndrome: clinical issues and management: a review. $B M C$ Pregnancy Childbirth. 2009;9(1):8. http://dx.doi.org/10.1186/1471-2393-98. PMid:19245695.

8. Chhabra S, Kakani A. Maternal mortality due to eclamptic and noneclamptic hypertensive disorders: a challenge. J Obstet Gynaecol. 2007;27(1):25-9. http://dx.doi. org/10.1080/01443610601016800. PMid:17365453.

9. Magee LA, Pels A, Helewa M, Rey E, von Dadelszen P, SOGC Hypertension Guideline Committee. Diagnosis, evaluation, and management of the hypertensive disorders of pregnancy: executive summary. $\mathrm{J}$ Obstet Gynaecol Can. 2014;36(7):575-6. PMid:25184972.

10. von Dadelszen P, Magee LA. Preventing deaths due to the hypertensive disorders of pregnancy. Best Pract Res Clin Obstet Gynaecol. 2016;36:83-102. http://dx.doi. org/10.1016/j.bpobgyn.2016.05.005. PMid:27531686.

11. Magee LA, von Dadelszen $P$, Rey E, Ross S, Asztalos E, Murphy KE, et al. Less-tight versus tight control of hypertension in pregnancy. $N$ Engl J Med. 2015;372(5):407-17. http:// dx.doi.org/10.1056/NEJMoa1404595. PMid:25629739.

12. Webster LM, Conti-Ramsden F, Seed PT, Webb AJ, NelsonPiercy C, Chappell LC. Impact of antihypertensive treatment on maternal and perinatal outcomes in pregnancy complicated by chronic hypertension: a systematic review and meta-analysis. J Am Heart Assoc. 2017;6(5):e005526. http:// dx.doi.org/10.1161/JAHA.117.005526. PMid:28515115.

13. Say L, Chou D, Gemmill A, Tunçalp Ö, Moller AB, Daniels J, et al. Global causes of maternal death: a 
WHO systematic analysis. Lancet Glob Health. 2014;2(6):e323-33. http://dx.doi.org/10.1016/S2214109X(14)70227-X. PMid:25103301.

14. Hutcheon JA, Lisonkova S, Joseph KS. Epidemiology of pre-eclampsia and the other hypertensive disorders of pregnancy. Best Pract Res Clin Obstet Gynaecol. 2011;25(4):391-403. http://dx.doi. org/10.1016/j.bpobgyn.2011.01.006. PMid:21333604.

15. Morse ML, Fonseca SC, Barbosa MD, Calil MB, Eyer FP. Maternal mortality in Brazil: what has the scientific literature shown in the last 30 years? Cad Saude Publica. 2011;27(4):62338. http://dx.doi.org/10.1590/ S0102-311X2011000400002. PMid:21603746.

16. Laurenti R, Jorge MHPM, Gotlieb SLD. A mortalidade materna nas capitais brasileiras: algumas características e estimativa de um fator de ajuste. Rev. Bras. Epidemiol. 2004;7(4):449-60.

17. Sibai BM. Diagnosis and management of gestational hypertension and preeclampsia. Obstet Gynecol. 2003;102(1):181-92. PMid:12850627.

18. Sibai BM, Taslimi MM, el-Nazer A, Amon E, Mabie BC, Ryan GM. Maternal-perinatal outcome associated with the syndrome of hemolysis, elevated liver enzymes, and low platelets in severe preeclampsia-eclampsia. $A m \mathrm{~J}$ Obstet Gynecol. 1986;155(3):5019. http://dx.doi.org/10.1016/00029378(86)90266-8. PMid:3529964.

19. Duley L. The global impact of pre-eclampsia and eclampsia. Semin Perinatol. 2009;33(3):1307. http://dx.doi.org/10.1053/j. semperi.2009.02.010. PMid:19464502.

20. Soares VM, de Souza KV, Freygang TC, Correa V, Saito MR. Maternalmortality due to preeclampsia/eclampsia in a state in southernBrazil. Rev Bras Ginecol Obstet. 2009;31(11):566-73. PMid:20084328.

21. Vigil-De Gracia P, Montufar-Rueda C, Ruiz J. Expectant management of severe preeclampsia and preeclampsia superimposed on chronic hypertension between 24 and 34 weeks' gestation. Eur J Obstet Gynecol Reprod Biol. 2003;107(1):247. http://dx.doi.org/10.1016/S03012115(02)00269-5. PMid:12593889.

22. Sibai B, Dekker G, Kupferminc M. Pre-eclampsia. Lancet. 2005;365(9461):785-99. http://dx.doi. org/10.1016/S0140-6736(05)71003-5. PMid:15733721.

23. Bartsch E, Medcalf KE, Park AL, Ray JG, High Risk of Pre-eclampsia Identification Group. Clinical risk factors for pre-eclampsia determined in early pregnancy: systematic review and meta-analysis of large cohort studies. BMJ. 2016;353:i1753. http://dx.doi.org/10.1136/bmj.i1753. PMid:27094586.

24. Duckitt K, Harrington D. Risk factors for pre-eclampsia at antenatal booking: systematic review of controlled studies. BMJ. 2005;330(7491):565. http://dx.doi. org/10.1136/bmj.38380.674340.E0. PMid:15743856.

25. Haddad B, Kayem G, Deis S, Sibai BM. Are perinatal and maternal outcomes different during expectant management of severe preeclampsia in the presence of intrauterine growth restriction? Am J Obstet Gynecol. 2007 Mar;196(3):237 e1-5.

26. Linhares JJ, Macêdo NM, Arruda GM, Vasconcelos JL, Saraiva TV, Ribeiro AF. Factors associated with mode of delivery in women with pre-eclampsia. Rev Bras Ginecol Obstet. 2014;36(6):259-63. http://dx.doi.org/10.1590/S0100720320140004812 . PMid:25099465.

27. Roberts JM, Pearson GD, Cutler JA, Lindheimer MD, National Heart Lung and Blood Institute. Summary of the NHLBI Working Group on Research on Hypertension During Pregnancy. Hypertens Pregnancy. 2003;22(2):109-27. http://dx.doi. org/10.1081/PRG-120016792. PMid:12908996.

28. Langenveld J, Ravelli AC, van Kaam $A H$, van der Ham DP, van Pampus MG, Porath M, et al. Neonatal outcome of pregnancies complicated by hypertensive disorders between 34 and 37 weeks of gestation: a 7 year retrospective analysis of a national registry. Am J Obstet Gynecol. 2011;205(6):540.e1-7. http://dx.doi. org/10.1016/j.ajog.2011.07.003. PMid:21907954.

29. Yücesoy G, Ozkan S, Bodur H, Tan T, Calişkan E, Vural B, et al. Maternal and perinatal outcome in pregnancies complicated with hypertensive disorder of pregnancy: a seven year experience of a tertiary care center. Arch Gynecol Obstet. 2005;273(1):439. http://dx.doi.org/10.1007/s00404005-0741-3. PMid:15834580.

30. Al-Jameil N, Aziz Khan F, Fareed Khan M, Tabassum H. A brief overview of preeclampsia. J Clin Med Res. 2014;6(1):1-7. PMid:24400024.

31. Gruslin A, Lemyre B. Preeclampsia: fetal assessment and neonatal outcomes. Best Pract Res Clin Obstet Gynaecol. 2011;25(4):491-507. http://dx.doi. org/10.1016/j.bpobgyn.2011.02.004 PMid:21474384.

32. Moura MD, Margotto PR, Rugolo LM. Changes of blood flow in the umbilical artery in hypertensive pregnancy and the implications in the neonatal outcomes. Rev Bras Ginecol Obstet. 2013;35(2):717. http://dx.doi.org/10.1590/ S0100-72032013000200006. PMid:23412006.

33. Martinez NF, Filgueira GC, Machado JS, Santos JE, Sandrim VC, Duarte G, et al. Clinical and laboratorycharacteristics of pregnant women with preeclampsiaversusgestational hypertension. Rev Bras Ginecol Obstet. 2014;36(10):461-6. http:// dx.doi.org/10.1590/SO100720320140005029 . PMid:25317825.

34. Brasil. Ministério da Saúde. Departamento de Informática do Sistema Único de Saúde (DATASUS). Indicadores e dados básicos: taxa de mortalidade neonatal. Brasília: 2012. [cited 2017 Sep 16]. Available from: http://tabnet.datasus.gov.br/cgi/ idb2012/c0104.htm

35. Sibai BM. Diagnosis, controversies, and management of the syndrome of hemolysis, elevated liver enzymes, and low platelet count. Obstet Gynecol. 2004;103(5 Pt 1):98191. http://dx.doi.org/10.1097/01. AOG.0000126245.35811.2a. PMid:15121574. 